\title{
HARE KRISNA
}

\author{
Jaume Vallverdú \\ DEPARTAMENT D'ANTROPOLOGIA SOCIAL I FILOSOFIA \\ UNIVERSITAT ROVIRA I VIRGILI. TARRAGONA.
}

\begin{abstract}
"¡Oh mejor entre los Bharatas (Arjuna)!, cuatro clases de hombres piadosos Me rinden servicio devocional: el afligido, el que desea riqueza, el inquisitivo y aquel que busca conocimiento del absoluto". Bhagavad-Gita, Cap 7, v. 16.
\end{abstract}

\section{Histðria: orígens, fundació $i$ expansi 6}

Per localitzar l'origen del sistema filosòfico-religiós Hare Krisna hem de remuntar-nos al saber oriental dels Vedes. Els fonaments de l'hinduisme i de la civilització hindú els trobem en la religió dels Vedes, que representa l'aspecte més antic en què es manifesten les formes religioses de l'India i el mateix pensament humà (Mahadevan, 1991:17)' ${ }^{1}$. Tot i que l'aspecte cronologic és poc precís, per algun autor el vedisme és introduït a la India nord-oest (el Punjab, conca de l'alt Indo) pels invasors aris entre el 2000 i 1500 abans de la nostra era (Renou, 1991:9). Es confondria amb el brahamanisme, com a religió de les èpoques antigues, mentre que hinduisme es referiria més a l'evolució religiosa a partir del període vèdic, que els textos històrics acostumen a situar entre el $1400 \mathrm{i}$ el $400 \mathrm{aC}$.

La paraula Veda significa "saber" o "coneixement" i el seu missatge escrit ens arriba a través de quatre col·leccions literàries (samhitas) considerades d'inspiració divina, que datarien aproximadament de l'any $1250 \mathrm{aC} .^{2}$ : el Rig-Veda o "Veda de les estrofes", constituït per himnes de lloança a diversos déus, el Yayur-Veda o "Veda de les fórmules" sacrificials, el Sama-Veda 0 "Veda de les melodies", una col-lecció litúrgica d'himnes seleccionats en la seva majoria del Rif. veda, i l'Atharva-Veda o "de les fórmules màgiques", que combina la religió vèdica i la filosofia amb els cultes $\mathrm{i}$ les pràctiques populars. Els comentaris a aquests llibres sobre els rituals i preceptes que els acompanyen van rebre el nom de Brahmanas ("interpretacions sobre el brahman").

Aquestes dues seccions de la literatura vèdica van denominar-se Sruti, "revelació" o "oïda" i se les considera d'origen diví, resultat d'una comunicació feta per vidència a certs humans privilegiats (poetes). La revelació inclou textos més breus, complements dels Brahamanas: els Aranyaka, "tractats forestals" o "llibres de la selva", que proporcionen les interpretacions filosofiques dels rituals a través de la seva al-legorització i prescriuen diverses formes de mediació, i els Upanishad o "aproximacions", tractats de tipus filosòfico-simbòlic sobre la naturalesa de la

\footnotetext{
${ }^{1}$ Aquest autor, citant a A. A. Mcdonell (1951), afegeix: "indudablemente el más antiguo monumento literario de las lenguas indo-europeas".

${ }^{2}$ Un informant Hare Krisna discrepa: "No, esos son cálculos de los arqueólogos modernos, pero según los propios Vedas, la literatura védica fue compilada por Vyasadeva hace cinco mil años, o sea, unos tres mil años antes de Cristo". (H., 28-I-93).
} 
"Realitat Suprema" que emfasitzen el saber i la meditació de la literatura bhakti, així com l'amor i la devoci $\sigma^{3}$. Relaten una gran epopeia anomenada Mahabharatha ("la gran guerra dels Bharatha"), on un dels personatges que apareix és Krisna (el "Suprem Atractiu"). Les ensenyances eotèriques que Krisna dóna al seu amic Arjuna al segon episodi (la batalla de Kuruksetra) es convertiran en el document filosòfico-religiós més important del sànscrit: el Bhagavad-Gita o "Cant del Benaurat".

El Bhagavad-Gita és el text sagrat central del Moviment Hare Krisna, juntament amb I'Srimad Bhagavatam i l'Sri Caitanya Caritamrta. El consideren la síntesi del pensament vèdic, ixi com ciència sagrada que, directament inspirada per la divinitat, domina tots els aspectes de lexistència. El Gita, conté les doctrines hinduistes més rellevants i transmet els tres camins de l'alliberament personal: el de l'acció, Karma-ioga, el del coneixement, Jnana-ioga, i el de la devoció o Bhakti-ioga. Aquest darrer és el practicat pels devots de Krisna, que el creuen el més complet i superior.

Els altres documents del vedisme pertanyen a l'Smriti o "tradició memoritzada". Són els Sura o "aforismes", textos redactats de forma molt concisa i densa on s'exposen les "veritats profundes" sobre el vessant interior de l'ésser humà. El Vedanta Sutra concretament, és, pels Hare Krisna, l'argument vèdic essencial.

Vyasadeva va ser el mestre compilador en sànscrit del coneixement vèdic. A partir d'ell, s'inicia una cadena de deixebles que arriba fins a Caitanya Mahaprabhu (1485-1533), un bengalí considerat la reencarnació de Krisna que impulsa el renaixement de la filosofia i pràctica exposada \Bhagavad-Gita. Amb la seva prèdica va difondre per tot el subcontinent indi que la forma més encilla d'obtenir el coneixement del jo era cantant els Sants Noms de Déu en la segũent sequència: Hare Krisna, Hare Krisna, Krisna Krisna, Hare Hare, Hare Rama, Hare Rama, Rama Rama, Hare Hare. Aquest Maha-mantra ${ }^{4}$ Hare Krisna s'interpreta com el cant transcendental que ta reviure el coneixement espiritual i condueix a l'autorealització.

\footnotetext{
${ }^{3}$ Upanishad també es tradueix per "ensenyança als peus del mestre" i la filosofia subjacent a tots ells (112 en total i duna extensió similar a la Bíblia) es va denominar Vedanta. La seva idea central és Brahman, que pot ser conegut en la wa manifestació d'ànima individual o atman a través del guiatge del mestre i la pràctica del ioga. El contacte amb aquesta "Realitat Suprema" implica aconseguir l'estat d'alliberament.
}

"A la revista "El espiritual", editada pel Moviment Hare Krisna s'explica: "El uso de mantras, vibraciones de Werminado poder específico, es muy antiguo. Los mantras pueden tener diversas finalidades, tanto materiales como mpirituales; entre todos ellos destaca un mantra puramente espiritual que fue propagado por el Señor mismo en Su usarnación como Sri Caitanya Mahaprabhu, el Maha-Mantra, el gran mantra: Hare Krisna, Hare Krisna, Krisna Krisna, Hare Hare, Hare Rama, Hare Rama, Rama Rama, Hare Hare. Este mantra de dieciseis palabras está compuesto por nombres to Dios (Krisna i Rama) y de su energía interna (Hare). (Vedavyasa, 1992:19).

Els mantres són paraules, sil-labes, o "vibracions sonores subtils" que, segons el saber oriental on s'arrelen i Vexperiencia de llurs pràctiques religioses, tenen un poder específic quan es reciten en estat de profunda contemplació moditativa. En pronunciar-los, ajuden a modificar els estats de consciència o les diverses possibilitats inherents a aquesta, tavorint aixf la introducció de la ment en una plataforma veritablement espiritual. Per una anàlisi acurada i basada en la viveccia directa, vegeu Blofeld, J. (1989).

Però tornant especificament al Maha-mantra Hare Krisna, un informant ens explica: "El mantra Hare Krisna se Lama Maha-Mantra, Maha quiere decir "gran" y la palabra Mantra es una palabra compuesta que significa liberación de L mente: man es "mente" y tra es de traya, "liberación". Es un canto que libera la mente, el gran canto de liberación de la mente. La finalidad que tiene es transportar el alma desde lo que es la dimensión material, digamos la vivencia corporal merna o incluso material sutil a nivel mental, transportarla a la plataforma espiritual, es decir, conectar el alma con la divinidad (...) Se le llama "vibración sonora trascendental"; trascendental quiere decir que está por encima de las leyes muteriales. De acuerdo a los Vedas desciende del mundo espiritual. Y lo que también dice la Biblia, que dice: "el principio on el verbo". Al sonido trascendental se le da una importancia especial en todas las escrituras sagradas y el canto de Hare Xisaa se considera así, proviene del mundo espiritual y por ese motivo la gente que lo canta tiene una experiencia diferente to que se experimenta común y corrientemente cuando se canta cualquier otra cosa. Atención, respeto y humildad son las scitudes más adecuadas para cantarlo" (H., 28-1-93). 
En el moment de desencarnar, Sri Caitanya va deixar un moviment solid, amb un nomber considerable de comunitats i seguidors. Alguns d'aquests seguidors, els Goswami, van fixar a doctrina Bhakti, que va continuar sent transmesa a través d'una cadena de deixebles la darren anella de la qual és Su Divina Gracia A.C. Bhaktivedanta Swami Prabhupada (1896-1977), mestr espiritual que portà a occident les ensenyances de Caitanya Mahaprabhu. L'any 1966 va fundx l'Associació Internacional per a la Consciència de Krisna (ISKCON) a Nova York, en plen agitació contracultural. Al llarg dels anys següents, i sota la seva direcció, Hare Krisna a desenvolupa progressivament fins convertir-se en una Confederació Mundial que no para d'obit temples i comunitats agrícoles d'orientació autosuficient. Abans de la seva mort, el 14 de novembr. de 1977 a Vrindavana (India), Srila Prabhupada assenyala personalment a alguns dels seus deixebles més avançats perquè el succeeixin en el govern d'ISKCON com a mestres espirituals. Deixarf darrera seu una societat fortament estructurada.

A Espanya, els Hare Krisna arriben l'any 1975 i funden els primers temples a Barcelon i Madrid. L'any segūent s'inscriuen en el Registre d'Entitats Religioses del Ministeri de Justíc amb el nom "Asociación para la Conciencia de Krisna". El Moviment té en l'actualitat uns cert membres actius, en una proporció aproximada de dos terços d'homes per un de dones, una mitjar d'edat que gira al voltant dels trenta cinc anys, i distribuïts majoritàriament per les comunitats de Barcelona, Màlaga i Brihuega (Guadalajara), aquesta última el principal "projecte" de l'Associacio a escala estatal. Cal aclarir que per membres actius s'entén devots que viuen als temples o prop d'ells, tot realitzant una tasca pràctica de servei, predicació, publicació, etc. D'altra banda, la congregació, estaria formada per uns dos-cents simpatitzants, que si bé no porten la vida de compromís estret de les comunitats, observen els principis regulatius i efectuen en la mesura de les seves possibilitats diferents activitats espirituals relacionades amb les creences Hare Krisna.

Durant els primers deu anys d'existència a la península, el grup segueix una tònica d creixement i arriba l'any 1985 a tenir un total de cent cinquanta membres. En aquest període, let energies dels devots es concentren a viatjar per la majoria de províncies espanyoles efectuant tasques de prèdica i distribució de literatura. L'any 1986 el Moviment pateix una crisi internacional que té especial transcendència a Europa. Srila Bhagavan, un dels mestres designats per Prabhupad i encarregat de la direcció organitzativa-espiritual de la zona europea, deixa el seu càrrec $i$ abandona l'Associació. Això produirà un considerable desajustament intern dels temples aleshores constituïts. Gairebé tots els membres espanyols havien estat iniciats per Srila Bhagavan i la sen deserció deixà a molts en el dubte de què havien de fer una vegada perdut el nord espiritual. Alguns van seguir els seus pasos, altres marxaren a l'India i, els que van romandre, foren reiniciats per altres mestres.

Però a la "caiguda" de Srila Bhagavan va afegir-s'hi la de dos mestres espirituals més, la qual cosa va obligar l'Associació a efectuar un replantejament a nivell internacional tant dels seus aspectes formal-organitzatius com dels derivats de les conductes internes dels seus membres, especialment alts càrrecs. Així, es va procedir a una revisió del paper de l'autoritat i del sistema de direcció de tipus assembleari en general. A efectes pràctics, això es tradú en el fet que i inicialment el mestre espiritual d'una zona determinada era l'únic que en podia iniciar els devots, en l'actualitat és el devot en persona qui escull el seu mestre. Tanmateix, a partir d'aquest moment, es tractarà que cada temple tingui la seva independència econòmica ${ }^{5}$ i es democratitzarà la direccí de l'Associacio; tot, amb l'afany de desenvolupar una vida estable en comunitat i evitar caure en errors del passat derivats de posicionaments fanatics $\mathrm{i}$ incoherents amb la realitat contextual.

5 Aquest projecte va fer-se realitat especialment a Espanya, però no a la totalitat de països on el Moviment implantacio. 
L'Associació per a la Consciència de Krisna s'autodefineix com una entitat religiosa formada r devots que practiquen el Bhakti-ioga o procés de servei devocional a la divinitat inspirat en el hagavad-Gita. En el Bhakti-ioga hi ha nou condicions de servei amorós i de devoció a Krisna: woltar, cantar, recordar, servir, adorar, resar, considerar-se un servent, fer amistat i lliurar-se mampletament.

Però si hem de parlar d'una tipologia doctrinal específica, el sistema de creences Hare lisma podria situar-se en el marc de l'hinduisme (o brahamanisme) devocional-personalista, que tt unes arrels molt antigues. El moviment bhakti, ja existent a l'època vèdica, presenta un Déu pronal centrat al voltant d'avatars o "encarnacions" divines en forma humana (tals com Krisna (prama) del tot diferents als éssers sobrehumans vèdics i als conceptes abstractes dels Upanishads wre la divinitat transcendent o brahman. En poques paraules: la seva expressió religiosa és l'amor il'adoració, implica la creença en una "Persona Suprema" en lloc d'una "Abstracció Suprema", ix centra al voltant de dues divinitats: Vishnu i Siva.

Sobre aquesta base, els precedents originals de la filosofia i pràctica Hare Krisna els watriem a la tradició vaishnava i, amb més precisió, en la seva tendència Bhakti-vaishnava hesa en el culte a Vishnu, el déu preservador del món, que amb Brahma el creador i Siva el kstructor representen els tres aspectes del Suprem. En aquest context, Krisna seria una de les deu mamacions de Vishnu, la vuitena en concret $^{6}$. Altrament, la tendència Bhakti-saiva emfasitzaria doulte a Siva.

En el pensament vèdic hi ha cinc conceptes essencials que serveixen de basament al conjunt (bososfico-religiós seguit pels devots de Krisna: Isvara, Jiva, Prakrti, Karma i Kala. Isvara significa (minitat (Krisna); per ells, la divinitat és només una, malgrat que pugui ser explicada de diferents meres. Jiva és l'ésser o ànima espiritual immutable i immortal, allo que realment som (el cos no b més que un vestit extern que desapareix amb la mort); consta de tres elements: eternitat, meixement i felicitat, i sovint està coberta per la consciència material contaminada, que priva la pasona de posseir-los. Prakrti significa naturalesa, i pot ser de dos tipus: material (constituïda per tra qualitats que influeixen les ànimes que viuen als cossos: bondat, passió i ignorància) i espiritual (a condició natural de l'ésser humà). Karma vol dir l'activitat o acció que fa l'ànima al món merial en pujar al seu vehicle transitori, el cos; en funció d'aquesta acció en una vida es renaix w unes condicions més o menys positives a la següent. Finalment, Kala, que significa temps; el mps es considera un element etern, una energia que fa que tot passi, es deteriori...és el factor structiu de l'energia divina. L'eternitat és una experiència individual a través de la posada en pretica de la saviesa vèdica, i aquesta pràctica no és altra que el Bhakti-ioga.

A partir d'aqui, concretant una mica més, tenim que:

VEl proposit fonamental que es desprèn del Bhagavad-Gita és la redempció de la humanitat de lecistència material. El Senyor Krisna descendeix expressament per restablir la veritable finalitat kla vida quan l'home se n'oblida: el retom al "cel Sanatana", que representa la "religió eterna" k l'ésser vivent. L'associació combinada del Senyor Suprem i les entitats vivents a l'"estatge" Leatana constitueix la perfecció de la vida humana. L'objectiu, en definitiva, és l'alliberament de thome del cicle de reencarnacions: "Esa, mi morada, no está iluminada por el sol, ni la luna, ni p la electricidad. Aquel que llega a ella, nunca regresa a este mundo material" (Bhagavad-Gita, 1978:304).

\footnotetext{
'Segons l'Srimad Bhagavatam, en la línea doctrinal seguida pels Hare Krisna: ";Oh, bramanas!, las encarnaciones del thor son innumerables, como riachuelos provenientes de inagotables manantiales de agua" (Cap. 3, v. 26). Però distingeix isayor Sri Krisna de la resta d'encarnacions: "Todas las encarnaciones anteriormente mencionadas son, o bien porciones marias, o porciones de las porciones plenarias del Señor, pero el Señor Sri Krisna es la Personalidad de Dios original". (cop. 3, v. 28).
} 
b/ La persona mundana està contagiada per quatre defectes: cometre errors, caure invariablement sota l'influx de la il-lusió, tenir tendència a enganyar els altres i raure limitada pels sentits imperfectes. En tals condicions, roman en consciència falsa o ego fals. En consciència pura (no condicionada o contaminada per allo material) les activitats s'acoblaran a la voluntat del Senyor $i$, una vegada completament purificades, es diran Bhakti, convertint-se en transcendentals a les tres modalitats de la naturalesa esmentades: bondat, passió i ignorància.

c/ Es considera que l'entitat vivent està en estat de demència si pensa que és lliure, ja que Krisna és el Suprem controlador i gaudidor. L'home, com a ésser subordinat i dirigit, està destinat a cooperar amb Krisna per satisfer-lo. L'ésser viu no és el cos material sinó una ànima espiritual creada per Déu i encarnada en un determinat cos (mutable) i té una relació eterna amb la divinitat, a la qual ha de servir de forma completa i exclusiva fent-li ofrena de les seves obres. El Senyor és perpètuament feliç, i si les entitats vivents s'associen amb Ell, aleshores també elles es tomen felices.

d/ L'essència de l'individu és el seu esperit; el cos pot morir però l'esperit no mor mai. Qui en el moment de la mort abandona el cos recordant solament Krisna s'integra immediatament amb la naturalesa divina.

e/ L'home tindrà un o altre destí en funció de les seves activitats en vida. Es parteix de la base que la vida humana pot acollir-se a dos sistemes cosmologics de concebre l'existència: el material $i$ l'espiritual. La vida material està presidida per la tendència a satisfer els desitjos corporals oblidant que l'ésser humà és una ànima espiritual, un temple de Déu; la vida espiritual, pel contrari, representa l'allunyament dels desitjos egoistes i les qualitats humanes negatives, per concentrar-se en el cultiu de la devoció a la divinitat (Krisna).

f/ La vida espiritual dels devots de Krisna es fonamenta en quatre actituds bàsiques: misericòrdia, puresa, austeritat o penitència i veracitat. Cal que observin quatre principis regulatius essencials: no menjar carn, peix, ni ous, no consumir drogues ni excitants, restringir el sexe al context del matrimoni i la procreació i evitar participar en jocs d'atzar, creadors de desitjos materialistes?' g/ El mètode pràctic per reviure la consciència de Krisna, com s'ha dit més amunt, és la vibració transcendental produïda pel cant dels Sants Noms de Déu o Maha-mantra Hare Krisna, que ha de recitar-se de manera individual un mínim de 1.728 vegades al dia mitjançant l'ús del japa-mala, rosari hindú de cent vuit comptes. D'altra banda, la recitació col-lectiva d'aquest mantra s'efectua bàsicament amb motiu de festivitats, sortides de presentació pública (Harinama) o distribució de literatura (Sankirtana) i de lloances conjuntes a les deitats.

h/ Quant a cosmogonia, participen de complexes teories sobre els cicles còsmics que arrenquen dels Puranes i d'altres col-leccions filosòfiques dels primers segles de l'era cristiana. Per ells, un cicle

\footnotetext{
${ }^{7}$ Representants d'una línia interpretativa molt concreta pel seu sensacionalisme i visceralitat antisectària com Rodriguer (1985) i Salarrullana (1990), tendeixen a afegir (gratuïtament) a aquests principis el de "no especular", fent-lo sindnim de "no pensar". Un informant ens explica el significat de "no especular" posant-lo en el seu context: "nosotros especificamente cuando hablamos de especular nos referimos a lo que es la especulación mental. Especulación mental quiere decir el cambir el significado, el sentido que en las propias escrituras se explica. O sea, por ejemplo, hay cosas que Krisna dice en h escritura, entonces, querer dar un propio significado, un significado inventado por uno mismo que no tiene nada que ver con el significado directo que ya está en la escritura. Eso sería especular o inventarse algo, inventarse una filosofia de vida Especular sería también hacer conjeturas, sería otra manera de decirlo. Hacer conjeturas sobre la vida, sobre Dios...ya tay una información directa que está ahí, en la escritura, y que viene en la cadena discipular, no hay necesidad de hacer conjeturas. Es un error confundirlo con "no pensar", con "no razonar"...porque la persona que acepta la evidencia védica como autoridad y que la acepta como una evidencia digamos sólida en sentido opuesto a lo que es la evidencia de la mente y los sentidos materiales, que se consideran imperfectos, ha aceptado la autoridad védica utilizando la lógica y el razonamiento. Existen argumentos lógicos y un razonamiento que le llevan a la persona a aceptar la evidencia védica y a no hacer conjeturas con su mente limitada. No es que no haya razonamiento, sino que incluso, hay muchos maestros que han sido grandes filosofos, lo cual demuestra que eran grandes pensadores, pero no aceptaban filosofias que provinieran del cálculo mental-material de una persona, o sea, filosofias hechas con los sentidos materiales y sujetas a los defector materiales" (H. 28-I-93).
} 
dsmic (mahayuga) comprèn quatre edats (caturyugas): Krtayuga (o Satyayuga), Tetrayuga, Duparayuga i Kaliyuga, l'era actual; aquesta és definida com la de la discòrdia i hipocresia i té ma durada de 432.000 anys, dels quals ja han passat cinc mil. Un cicle complet acaba amb una "issolució", un pralaya, que es repeteix d'una manera més radical (mahapralaya, la "gran issolucio") al final del mil·lèsim cicle ${ }^{8}$.

\section{1.rganització: articulació general del Moviment}

En els seus darrers dies, Srila Prabhupada, amb l'objecte de no concentrar la direcció del koviment en una sola persona, creà el Consell Mundial o GBC (Governing Body Commission). Mquest organisme està constituit per uns trenta mestres espirituals representants dels diferents pissos en què l'Associació té implantació, s'organitza en un marc democràtic de decisions i es raneix anyalment per establir les línies d'actuació respecte al funcionament general dels diferents mples. Cada membre és responsable administratiu i espiritual de les comunitats situades en una tra geogràfica determinada, i la seva funció principal és la de vetllar per la correcta gestió Pquestes a través del contacte regular amb els presidents nacionals.

D'altra banda, a nivell específicament espiritual, el guru o mestre esdevé un personatge clau n l'Associació per a la Consciència de Krisna. Com s'expressa en el seu text normatiu: 'bicamente a aquellas grandes almas que tienen una fe absoluta tanto en el Señor como en el mestro espiritual, se les revelan todos los significados del conocimiento védico". Tanmateix: 'ndie puede aproximarse directamente a la Suprema Personalidad de Dios. Es preciso hacerlo por modiación de sus devotos puros. Por lo tanto en el sistema vaishnava, el primer deber es aceptar mo maestro espiritual a un devoto y luego prestarle servicio" (Vedavyasa, 1983:7). Així, tres roceptes bàsics són: buscar refugi en un mestre espiritual autèntic, ser iniciat per ell i aprendre mb el seu ajut a executar correctament el servei de devoció. El devot escull un mestre espiritual therminat, al qual entrega el guiatge de la seva vida i rendeix una obediència absoluta; només raquesta manera podrà apropar-se gradualment al coneixement de si mateix i a la Consciència de IEsser Suprem. Entre ambdós s'estableix un lligam molt fort, una relació de plena confiança i una inportant reciprocitat comunicatiu-observadora.

González López (1983:323) senyala molt adequadament les característiques essencials del veritable guru: a/ la seva ensenyança ha de ser totalment espiritual. No s'aprofita dels seus texebles per obtenir béns materials; b/ ha d'haver arribat a la més alta realització de la veritat wsoluta; c/ ha rebut el coneixement d'un mestre espiritual autèntic i el transmet sense modificar-lo; $\checkmark$ ha de portar una vida santa i observar estrictament tots els principis religiosos; e/ glorifica xmpre el Senyor Suprem i incita altres persones a fer el mateix; f/ sobretot, s'ocupa de difondre per tota la Terra el missatge de la consciència divina.

Espiritualment, es distigeixen quatre grans ordes (ashramas) pel que fa a la classificació jerarquica dels membres masculins del Moviment (les dones -"mares"- només es categoritzen com ad libes o casades): Brahamacari, Grijhasta, Vanaprastha i Sannyasa-swami. Els Brahamacaris '́nomenen també estudiants cellibes. Aquesta categoria estaria integrada pels nascuts dins del grup on un període que va des dels cinc fins als vint-i-cinc anys aproximadament o pels adults de

\footnotetext{
'Sobre la mitologia de la creació i destrucció cíclica del Món i la creença en la "perfecció dels començaments" vegeu, wt exemple, Eliade, M. (1979). Pel que fa al tema escatologic que ens ocupa, aquest autor diu: "Según el Mahabharata y buranas, el horizonte se inflamará, siete o doce soles aparecerán en el fírmamento y secarán los mares, quemarán la Tiem. El fuego Samvartaka (el fuego del incendio cósmico) destruirá el Universo por completo. A continuación, una lluvia Uiluvial caerá ininterrumpidamente durante doce años, y la tierra quedará sumergida y la humanidad aniquilada (Visnu hrena, 24, 25). En el Océano, sentado sobre la serpiente cósmica Çesha, Visnú duerme sumergido en el sueño yoga (Visnu hrana, VI, 4, 1-11). Y luego todo recomenzara de nuevo ad infinitum" (Eliade, 1985:67-68).
} 
procedència externa que, després de ser iniciats, entren en preparació espiritual fins que es casea o fan els vots definitius de renúncia. El devot brahamacari estudia les escriptures, serveix el meste espiritual i altres devots i cultiva les qualitats contemplatives; posteriorment, decidirà si desitgy casar-se o bé romandre en estat de renúncia tota la vida. S'adopta per indumentària el color safrut que indica celibat. L'orde de Grijhasta es defineix com la de vida familiar i de treball actiu. Qua el devot es casa, els seus compromisos amb el temple disminueixen, ja que com a cap del nuó familiar ha de dedicar especial atenció al manteniment del mateix. En aquest cas s'adopta el cola blanc, símbol de puresa. A partir dels cinquanta anys, els homes casats poden iniciar un progressin allunyament de la família. En aquesta etapa, anomenada Vanaprastha, el devot inicia una vid retirada orientada a deslligar-se a poc a poc dels vincles terrenals i preparar-se per la renúncis definitiva, formalitzada finalment en l'orde de Sannyasa. Llavors es produeix una desvinculacid radical de les propietats materials, s'està lliure de relacions familiars i totes les activitats a dediquen per complet a Krisna; el cultiu espiritual intern i els constants viatges de predia subvencionats pels devots dels diferents temples són les ocupacions fonamentals dels swamis. Cal puntualitzar que les dones no prenen aquesta orde; en cas que el marit renunciï, l'esposa romandid protegida pels fills o s'instal-larà a un ashram de "vídues".

Els quatre ordes mencionats constitueixen un cicle sencer pel qual hauria de passar tot devo de Krisna. La primera etapa és formativa i de lliurament al servei devocional. En la segon s'adquireixen les responsabilitats familiars i es realitzen activitats dirigides al desenvolupament de Moviment. Al final, les dues darreres representen reprendre el camí de dedicació exclusiva a b divinitat en el marc d'una vida austera, contemplativa i de prèdica espiritual.

\section{Forma de vida: rutines quotidianes, economia $\mathbf{i}$ organització interna}

La vida dels devots Hare Krisna s'organitza al voltant del temple, que pot adoptar un funció eminentment pública en cas d'ubicar-se en zones urbanes o bé eminentment espiritual $\dot{\text { s }}$ s'estableix en forma de comunitat agrícola. En el primer, predicar és l'activitat fonamental; b finalitat és donar a conèixer i difondre el missatge filosòfic i pràctic del grup. En el segon, d principal objectiu és desenvolupar la vida de la Consciència de Krisna en la seva versió més genuina, tal i com ho recomanà el fundador.

El programa espiritual del temple delimita l'horari vital de la comunitat, que comença a les quatre de la matinada i acaba aproximadament a les nou del vespre. L'horari de treball en un granja agrícola, tot i ser força flexible en funció de necessitats puntuals, s'estructura entre les 10 $i$ les 2 del matí $i$ les 4 i les 7 de la tarda. De 8:30 a 9:30 s'efectua el primer menjar, de 14:30 a 15:30 el segon i al voltant de les 20:30 pot prendre's una petita quantitat de llet o d'infusió.

Per compromís amb els vots efectuats, és bàsicament qüestió de responsabilitat personal (en especial pels cèlibes) aixecar-se a les quatre de la matinada per iniciar el programa diari al temple. La primera cerimònia (de 4:30 a 5) és el Mangala arati, que significa el retrobament amb les deîtats $\mathrm{i}$ on l'adoració a l'altar es combina amb el cant $\mathrm{i}$ la dansa rítmica dels devots que la contemplen i de la qual participen. Tot seguit, s'efectua un acte de lloança a una planta d'alta significació espiritual en les escriptures vèdiques, que té la seva expressió central en el fet de regarla ritualment; és l'anomenat Tulasi puja (de 5 a 5:15). A les 5:15 comença la recitació del Mahamantra Hare Krisna o cant del Japa-mala en total estat de concentració. Aquesta meditacio individual es perllonga fins a les 7 del matí, hora en què tornen a presentar-se i venerar-se breument les deïtats. Seguidament, té lloc el Guru-puja (de 7 a 7:15), un ritual d'adoració al mestre fundador en el qual l'animat cant i ball dels devots acompanya l'ofrena individual de pètals de flors. El Kirtan (de 7:15 a 7:30) consisteix en diversos cants devocionals a ritme d'instruments musicals dirigits de nou a l'altar. Després d'alguna curta lectura sagrada, a les 7:30, un devo avançat imparteix una classe de filosofia d'una hora de durada aproximadament basada en un del 
tutos principals: 1'Srimad Bhagavatam. De 8:30 a 9:30 es pren prasada', el primer aliment del a prèviament consagrat per les deïtats. A continuació, cada devot es dirigeix a l'activitat o funció a te té encomanada fins a l'hora del segon àpat. Els diferents serveis/càrrecs a la comunitat ocupen it voltant de sis o set hores diàries entre matí $i$ tarda, i bàsicament són els següents: president, viceprident, secretari o administrador, cap de departament, comandant de temple, cap d'adoradors, woradors, cuiner de les deittats, cuiner dels devots, oficines i correspondència, tasques agrícolesamaderes, neteja, garlandes, manteniment d'edificis, confecció de vestits, traducció, llar d'infants iaidador de la planta Tulasi. La tarda, després de prendre el prasada, és bastant més relaxada a ivell de serveis i complementàriament a aquests pot dedicar-se a la meditació, a l'estudi, o bé a mbar les rondes de japa que han quedat pendents. A partir de migdia (12:30) i fins a les 21:30 a reprèn la sistemàtica cerimonial; Rhaja Bhoga arati, Dhupa arati, Sandhya arati i Sayanna miti completen la seqüència ritual del dia pel que fa a l'adoració i lloança de les deïtats. Thmateix, es considera important l'assistència a la segona classe de filosofia (de 19:30 a 20:30) wbe el Bhagavad-Gita. Durant els caps de setmana, la formació tedrica s'arrodoneix amb la letura i comentari de la biografia del fundador i de l'Sri Caitanya Caritamrta.

Aquest règim normalitzat de vida contemplativa de la comunitat només es veu alterat els tusebtes a la tarda, en què al voltant d'una quinzena de devots es traslladen a Madrid per fer Barinama o cant i ball amb instruments pel carrer. Els diumenges a mitja tarda, d'altra banda, iefectua un petit convit vegetarià al qual solen acudir algunes persones que formen part de la mngregació o bé amistats.

La granja agrícola Nueva Vrajamandala de Brihuega va comprar-se a finals de 1979 per uns xixanta milions de pessetes i en l'actualitat acull quaranta quatre membres adults -la majoria Porigen estatal- i deu nens, xifra en què s'ha mantingut la seva trajectòria demogràfica.

Tot i fent-ne una mica d'historria, val a dir que inicialment la comunitat era bastant reduïda iestava molt freqūentada per membres americans $i$ altres devots estrangers deixebles directes del fundador que ocupaven les cases que envolten el temple. El període 1976-1985 va ser una època d'assentament i de creació d'una infraestructura adequada per obrir centres permanents a Espanya. La direcció espiritual d'aquests centres de nova creació anava a càrrec dels devots americans i woptava formes de funcionament intern molt rígides $\mathrm{i}$ fanàtiques, que incloïen elements força bsorbents i sectaris ${ }^{10}$. Entre els devots espanyols gairebé no n'hi havia cap de casat i la seva cupació fonamental era la distribució de literatura de manera intensiva amb l'objecte de recollir ds fons necessaris per desenvolupar el Moviment a la península. Entre els anys 1985 i 86 van produir-se molts enllaços matrimonials, la qual cosa suposà una menor dedicació a la prèdica en tavor d'un major aprofundiment en la vida comunitària a nivell de creació de famflies.

La propietat, ubicada en plena Alcàrria, té un total de 308 hectàrees de terreny i és

\footnotetext{
'Qualsevol preparació d'aliments que s'ofereix a les deïtats rep el nom de prasada, literalment, misericòrdia. L'aliment procedent de l'ofrena directa a Krisna s'anomena Maha-prasada (gran misericordia).

${ }^{10}$ Textualment d'un informant Hare Krisna: "En aquella època hi havia molta ansietat. Era una cosa que estava fora w w puesto $i$ això em va xocar bastant. Erem una secta...la finalitat era la mateixa i era igual de bona ¿no?, ara, com es prtaven moltes coses...realment estaven fora de lloc. Ara, Krisna ha fet els arreglos i tot s'ha precipitat per una altra forma, 1o aquí sinó a altres puestos també, $i$ ha posat les coses al seu puesto. Però que...havia una adoració absurda, una cosa motimental, una cosa sense aquest...sense filosofia i sense...simplement per la presència d'un senyor (Bhagavan) i que matrava a les persones. Ara, estem a l'altre extrem". (T., 31-I-93).

Aquests primers temps, seguint els comentaris d'alguns informants, $s$ 'haurien caracteritzat pels ritmes vitals beotetics, una pràctica espiritual gairebé compulsiva i una sistematització i regulació molt estricta de totes les activitats. Aquest tipus de comportament s'associa a l'eclosió entusiasta i ambiciosa del Moviment $i$ al fanatisme dels seus líders, factors we van portar a cometre "molts errors que encara es paguen a nivell d'imatge exterior", tot i el major aperturisme social aistent.
} 
travessada en diagonal per les aigües del riu Tajuña. Els edificis principals ocupen el centre $\alpha$ l'extensió i alberguen el temple, les habitacions de devots i devotes en celibat separadament, h cuina, la biblioteca i la resta de dependències comunitàries. Les cases dels devots casats s'estena properes al voltant d'aquest nucli.

La base general de l'economia Hare Krisna són les donacions, que provenen de quatr punts: la congregació, que col-labora sobretot per a l'execució de projectes específics, la comunitr hindú, els membres que treballen en algun negoci propi, habitualment centrat en el comert d'articles procedents de l'India, i els equips de distribució de llibres. D'altra banda, les unitbs familiars instal-lades a la granja tenen relativa autonomia economica. Entre aquestes, $\mathrm{n}$ 'hi ha que estan molt dedicades al desenvolupament del "projecte" del temple en tots els seus aspectes, $i$ aquest, en reciprocitat, els ofereix un habitatge i també alimentació en cas que ho desitgin. Peid les despeses pròpies solen cobrir-les amb algun petit negoci particular que fins i tot els permet a ocasions aportar alguna quantitat mensual al temple. En aquest sentit, es diu que la contribució $\alpha$ les famflies que viuen $i$ treballen permanentment fora de l'àmbit comunitari no acostuma a ser mi tan solida com aquesta.

L'estratègia econòmica principal de la granja, agrícola-ramadera, s'orienta a potencirs l'autosuficiència, que ja s'ha aconseguit en cereals i vol fer-se extensible a la resta de producta bàsics per a l'alimentació (estrictament lacto-vegetariana). Es disposa d'un total de vint-i-cix hectàrees de terreny cultivat entre regadiu i secà, fragmentat en vint-i-sis parcel-les de diferat grandària situades a banda i banda del riu. El servei de tasques agrícoles i ramaderes s'organitz en el marc del departament "agro-vaques", constituït per un petit grup de devots amb dedicacib plena. En els períodes que requereixen més força de treball comencen les labors comunitàries, a les quals participen la majoria dels membres de la granja, a excepció d'aquells que estan realitzar serveis imprescindibles. El temps invertit en tasques agrícoles i ramaderes és aproximadament d'unes set hores diàries, si bé l'horari es flexibilitza en funció de les necessitats del cicle de produccio-recol-lecció. El sistema d'agricultura seguit és el biològic o ecologic; d'acord amb h filosofia "la terra és la nostra mare natural" es prescindeix de l'ús d'insecticides i productes químia per a l'adob. Tanmateix, s'efectua un sistema rotatiu de guaret o alternança productiva anyal amb l'objecte de regenerar la terra. L'horta produeix tot l'any gràcies a l'adob natural que proporcionea les vaques, i els camps de cultiu, en la seva època de descans serveixen de pastura al bestiar, qux al mateix temps prepara el terreny per a l'any següent. En l'actualitat el ramat és de vint animals, vuit bous i dotze vaques.

Si la mà d'obra masculina és la que predomina en el sector agrari i ramader, en el marc ma general de la divisió sexual del treball, cal dir que se segueix la distinció més tradicional de rob assignats a cada gènere. Aix́, les dones s'encarreguen bàsicament de les tasques domèstiques, de l'atenció dels infants, de feines de costura, confecció de collarets de flors, etc., mentre que ets homes ho fan de les de tipus organitzatiu, intel-lectual i que requereixen l'aplicació de força físia

La gestió financera va a càrrec del president, que junt a dos líders de cada departamenti petits comitès de treball, unifica criteris per a la presa de decisions ja sigui en el Consell de temple o de forma autònoma. En conjunt, l'administració dels fons s'organitza segons uns pressupostor elaborats partint dels ingressos propis i la quantitat de donacions exteriors.

Fins aquí la quotidianeitat i l'economia. Entrem ara en el camp de l'organització intern La composició familiar Hare Krisna és de tipus nuclear i la terminologia de parentiu, es correspon amb l'ús occidental més generalitzat. Amb l'objecte que l'atmosfera espiritual de la comunitat en mantingui, s'exigeix el compliment estricte de la normativa relativa al contacte físic $i$ verbal entr ambdós sexes, doncs s'entén que la conversa informal o mundana tendeix a degenerar en actituds poc recomanables espiritualment. La finalitat de la relació de festeig i del matrimoni formalitzat, segons la línia filosòfica del grup, no ha de centrar-se en la intimitat dels contactes sinó en vessant espiritualista i a aconseguir una desafecció recíproca entre els membres de la parella. E aquest sentit, la vida conjugal implica un contacte que si no és molt vigilat pels mateixos casats pot 
monduir a una "caiguda", la qual, malgrat expressar-se en diferents modalitats, convergeix en el fet k tenir relació sexual fora dels principis religiosos. Així mateix, la sacralització de la unió utrimonial fa que regulativament no es permeti ni la separació ni el divorci; si la parella entra en kevinença, es permet una separació pel temps que els seus membres creguin oportú i perquè dservin la possibilitat de reconciliar-se, però en cap cas es poden tornar a casar amb un/a altre/a krota.

Pel que fa a l'educació infantil, l'Associació ja fa temps que està efectuant gestions legals *a poder crear la seva pròpia escola (Guru-Kula). El sistema educatiu a implantar intenta, d'una inda, seguir les directrius vèdiques, que combinen l'ensenyament de matèries acadèmicament thiques amb el cultiu espiritual i, d'una altra, instituir la convivència permanent mestre-deixeble. bal'actualitat, la majoria de nens són enviats a l'escola pública local amb totes les contradiccions - tologiques/formatives i pràctiques que això suposa. Es una opció que no satisfa als membres de h comunitat però, de moment, esdevé la més viable. L'altra possibilitat, molt més complexa i woptada només per uns pocs, és costejar l'educació dels infants a l'India.

Quant a l'aspecte mèdico-sanitari, el referent ideal és el sistema de curació Aiurvedic, el mncepte bàsic del qual és la capacitat de l'individu per l'autocuració ${ }^{11}$. Però donada la manca Vespecialització en aquesta ciència fora de l'India, el grup es decanta en general vers la medicina unural, si bé no hi ha una recomanació explícita i obligatòria d'utilitzar-la com a alternativa a la monvencional. La decisió és una qüestió essencialment individual i està en funció de les arrumstàncies de salut en què la persona es trobi.

Finalment, i per fer esment d'alguns temes puntuals relatius a elements fisics externs, els lomes es vesteixen amb el característic dhoti hindú o tela àmplia adaptada a la part inferior del cos il kurta, peça usada a manera de camisa, essent ambdues del color que correspon a l'estat minitual del devot; les dones, per la seva banda, ho fan amb l'anomenat sari o vestit de colors larg que s'acompanya d'una manteleta per cobrir el cap. Els membres masculins s'afeiten el cap wm a mostra de renúncia, deixant-se una cueta (sikha) a la part posterior que simbolitza el caràcter pasonalista en la concepció de Déu segons la filosofia del grup. A més, devots i devotes marquen dus seus fronts amb un senyal de fang (tilaka) indicant que el cos és un temple de Krisna.

\section{S. Iniciació: adoctrinament $\mathrm{i}$ conversió}

La persona que arriba a la comunitat, ja sigui perquè està especfficament interessada a mneixer la filosofia i creences del grup, per simple curiositat després d'haver rebut el convit valgun devot o per qualsevol altre motiu (repos, retir espiritual, desintoxicació ${ }^{12}$ etc.) no rep en principi cap impediment per estar-s'hi un periode de temps, determinat o no. Aix s'emmarca dins

"A mode introductori vegeu, per exemple, Vasant Lad (1991).

${ }^{12}$ Nguns individus acudeixen a la granja amb l'objecte explícit d'eliminar la seva addicció a l'alcohol o a la droga, unors que la forma de vida ascetica i naturalista del grup i la rigorosa disciplina del seu programa espiritual pot mpresentar una gran ajuda a l'evitació definitiva d'aquestes substancies. Encara que l'interès espiritual sigui secundari o wistent en un principi, el procés sòcio-religiós pot instal.lar-se de forma permaneat a la vida de l'afectat en cas que puibiliti el guariment; de fet, algun informant reconeix que hi ha exemples de persoses "totalmente deshauciadas cuando hyron" que són ara "los mejores devotos" i estan "muy avanzados espiritualmente". De totes maneres, sembla que mijritàiament el problema només té solució si la persona està decidida a renunciar per complet als productes tòxics i a wir-se als imperatius normativo-pràctics de la comunitat, centrats en la vida contemplativa $i$ la negació sistemàtica de les ctitsds materialistes i consumistes occidentals. El fet d'abandonar la comunitat sovint significarà recaure i quedar-s'hi npereix un esforç constant al qual no tothom està disposat. En poques paraules: el cesig real ha de predominar sobre el mamatisme. 
la lògica general que l'hospitalitat és un pilar bàsic del pensament Hare Krisna i respon també̀ una necessitat concreta: la incorporació de nous membres. En el cas que aquesta persona no: costegi el sojorn, ha de participar de forma activa en les cerimonies i activitats que es desenvolupe a la granja, sempre que -segons l'autoritat instituïda- demostri tenir una sèrie de valors humas mínims i sentit de la responsabilitat en els seus actes ${ }^{13}$. Aquesta participació ha d'impliar l'amotllament progressiu a la forma de vida del col-lectiu, tant a nivell de ritme vital (horah alimentació,...) com de serveis i consumació del programa espiritual. Es considera una "fast. d'entrenament" i és observada amb atenció, sent la demostració efectiva de respecte $\mathrm{i}$ interta l'aspecte més valorat.

Paralel-lament, si ho creu convenient per completar la seva experiència en la dinàmia comunitària, l'individu pot començar un curs d'iniciació al Bhakti-ioga, que consisteix a l'ensenyança tedrica dels punts claus de la filosofia vèdica i la seva aplicació en la practia devocional diària. Aquest curs té una durada de tres mesos, després dels quals es potencia un formació més individualitzada mitjançant l'estudi dels textos sagrats principals. En tot aquest temp en definitiva, la persona ha rebut una informació específica i ha experimentat els efectes d'u programa espiritual; a partir d'aquí, se suposa que està en condicions d'analitzar la situació decidir si vol continuar el procés amb l'objecte d'integrar-se al grup o abandonar ${ }^{14}$.

A l'individu que decideix seguir i preparar-se per a la iniciació se'l denomina bhakta -sits home- o bhaktin -si és dona-. Durant aquest període s'exigeix al neòfit el seguiment estricte de programa espiritual i la satisfacció d'un nombre fix de serveis a la comunitat. Es contemplen la seves qualitats i defectes, i a excepció que mostri algun tipus de problemàtica personal o relacional, no es posa cap impediment a la integració. Això sí, és creu del tot imprescindible valorar h constància i estabilitat en la pràctica espiritual i avaluar l'avançada en el coneixement filosofic.

Sol passar com a mínim un any de preparació abans, que l'estudiant cèlibe obtingui h primera iniciació. Durant aquest any ha d'haver cantat setze rondes diàries de japa, seguit amb fermesa els principis regulatius i demostrat una dedicació estable. Una vegada ha escollit mestu i el president de temple ha donat el vist-i-plau a la iniciació tot enviant al guru les recomanacions adients, cal que passi un examen escrit on testifiqui que disposa d'un coneixement teòric bàsic. Pur últim, el mestre espiritual, si està d'acord en acceptar-lo com a deixeble, li donarà un nom. Després d'un altre lapse de temps variable, normalment de dos o tres anys, i també prèvia recomanació del president de temple, el devot prendrà la segona iniciació en una elaborada cerimònia de foc. Aquesta no implica canvi de nom, reafirma el compromís de la primera iniciació, indica l'accés a l'orde de renúncia i confereix accés a l'adoració de les deitats. En el procts simbòlic-ritual el mestre lliura al deixeble el cordó brahmínic i un mantra específic que s'ha de recitar en silenci i plena concentració tres vegades al dia.

\footnotetext{
${ }^{13}$ Altrament, l'estada a la granja com a "convidat" no implica un règim de participació rigorós i normalitzat, si bé d més frequuent és que la persona, per ètica i convivència, procuri adaptar-se el més possible als paràmetres sòcio-religion de la comunitat.

${ }^{14}$ Textualment d'un informant Hare Krisna: "una vez esa persona ha recibido una información, a lo mejor eso le llen a plantearse cosas que no se había planteado o se las planteaba en un pasado muy lejano y de una manera...sin muctu profundidad, y eso ya le puede hacer pues que esa persona...que digamos su corazón se abra a la vida espiritual (...) En es una experiencia que le queda igual para el resto de su vida, aunque no la practique porque le cuesta seguir esos principia. Yo estoy seguro que en la mayoría de los casos les marca y se quedan con una impresión positiva, la mayoría. Pero h mayoría no se quedan, lo cual demuestra que de lavado de cerebro no, que es una elección propia del individuo, simplemente". (H., 22-X-92).
} 


\section{Relacions amb altres institucions socials}

El desenvolupament del present apartat s'ha de centrar al voltant de la ja apuntada dicotomia estructurant de la cosmologia Hare Krisna: espiritualitat vs materialisme. Es a partir d'aquesta que es construeix la identitat dels membres de l'Associació i s'organitzen els sistemes de relacions amb Itres instàncies socials. Ser devot acredita pertànyer a una categoria perfectament definida i molt devada, per contraposició al referent materialista predominant a Occident i amb el qual s'està en bal desacord. El marc espiritualista constitueix el "nosaltres" que implica una radical distinció reppecte a "ells", "els altres" o "la resta", i indica tant fraternitat de vida i objectius com el fet J'estar en possessió d'un "saber absolut" al qual no tothom té el privilegi d'accedir. Aquest exclusivisme simbòlic $\mathrm{i}$ ideològic determina la configuració de les relacions individuals $\mathrm{i}$ institucionals del Moviment, en el sentit que proporciona una base identitària consistent $i$ unívoca que difícilment es veu alterada per circumstàncies externes al grup, sempre situades en un plànol de transcendència inferior $i$, per tant, només parcialment dignes de consideració pel que fa als seus missatges i processos interactius.

Però la tendència "totalitzant" i conseqüent delimitació d'un "món social" diferencial o ingroup, no estaria aquí tan representada per condicions de tipus físic, és a dir: "pels obstacles que ioposen a la interacció social amb l'exterior i l'èxode dels membres, i que solen adquirir forma material: portes tencades, alts murs, filferro de pues, penya-segats, rius, boscos o pantans" (Goffman, 1988:17-18) com per "la naturalesa mateixa de l'estatus i els privilegis" (Coser, 1978:15) d'aquests membres. En aquest sentit, la institució "concentraria l'adhesió de tots els seus membres, o de part dels seus membres, en un estatus general i llurs respectives relacions fonamentals de paper. Exclòs de tota relació competitiva, i sense bases externes on fundar la seva identitat social, aquest grup selecte d'ocupant d'estatus fundaria la seva identitat en l'univers simbolic d'un limitat conjunt de papers" (Coser, Op. cit., 17).

Un dels detonants i també efectes de la situació acabada de plantejar seria la debilitació de vincles anteriors a l'ingrés en el grup i l'alternació de la xarxa social dels individus-membres. Però on el cas dels Hare Krisna, aquesta modificació relacional no estaria motivada per l'impuls de mecanismes de pressió coercitiva o per l'impediment normatiu de contacte amb altres institucions o sectors societals. L'esmentada dissonància simbòlico-ideològica respecte a l'out-group tindria el sev origen en factors previs de "no coincidència amb el món" i/o de "buscar quelcom més", i es consolidaria progressivament en el decurs de la iniciació i del desenvolupament devocional com a resultat d'un procés acumulatiu d'identificació i construcció identitària. Una vegada es produeix la definitiva conversió religiosa, tal dissonància adquireix ple sentit en el marc d'un trasvassament cultural i filosòfic de tipus estructural que repercuteix sobre tots els rols i actituds de l'individu.

Per tot aixo, en l'àmbit de les experiències personals, hauríem de parlar d'una complexa suma de factors vitals emmarcats en una conjuntura sociològica determinada (la derivada, pel que fra als devots de Krisna ja estabilitzats al Moviment, del fenomen contracultural de la dècada dels setanta $\left.{ }^{15}\right)$ i que estarien en relació amb una manca generalitzada de feeling respecte als models d'identificació dominants a partir dels quals l'individu informa i conforma la seva identitat. Aixo facilitarà que, en la majoria dels casos, es trobin explicacions efectives en una mena de "totalisme integrador" marcador d'una frontera simbòlica respecte al context occidental (projectada inicialment a nivell cognitiu en forma d'armadura d'autoprotecció/reafirmació) que funciona de plataforma

\footnotetext{
${ }^{15}$ Textualment d'un informant Hare Krisna: "En la primera época venía mucha gente de esta...bohemia, que tomaba drogas, que iban por las ramblas de Barcelona y que se acercaban; de ahí salieron algunos muy buenos que están todavía, quentonces se hicieron o por la moda o por lo que fuera, que luego cada uno dentro de sí tenia su búsqueda (...) Había ucho movimiento, supongo que también por la cosa de la época. En esa época había gente que viajaba de aquí para allá, peate bohemia (...) Ahora no hay tanta gente como antes que venían y se unían; ahora la criba que tenemos es más cerrada, que sean pocos pero si permanecen..." (H., 10-VII-92).
} 
d'expressió adequada a "identitats latents" fonamentades en la recerca introspectiva existencialista ${ }^{16}$. Aquestes identitats, explotarien en trobar tal plataforma per estar-hi sintèticamer i globalment encaixades.

Així, la progressiva desvinculació dels membres de part de la seva antiga xarxa social s'te d'entendre en el context de la resocialització o reenculturació en uns paràmetres valoratiusi comportamentals totalment diferents, i que només és possible si parteix d'un desig real de carux ontologic per part d'aquells que l'experimenten. Són les noves orientacions cognitives producte de l'entrenament i l'aprenentatge voluntari les que proporcionen una "visió del món" i unes pautu d'actuació que per la seva pròpia lógica intrínseca impliquen un allunyament de la vida socid general, amb la qual deixen d'existir punts de connexió estructurals però es mantenen connexiors necessaries $\mathrm{i} / \mathrm{o}$ inevitables. Així, les relacions amb altres institucions socials (religioses, estatalh familiars, etc.) queden restringides a qüestions essencialment pràctiques. Aixd és, aquelles qu afecten de forma directa l'organigrama operatiu intern de l'associació en allò tocant a estratègia econòmiques i productives (el grup té contacte amb un monestir catòlic proper i amb agriculton veïns), a aspectes de tipus administratiu/legislatiu que condicionen la gestió de les comunitats o det seus diferents projectes infraestructurals (com ara la creació d'una escola pròpia), a participació a trobades entre diferents col-lectius religiosos o d'orientació naturista, a situacions de tracte amb la famílies pel que fa a la incorporació de nous membres i comunicació amb ells, etc. En relació ant aixd últim cal afegir, a més, que el coneixement universalista adquirit a la institució, en permetr "explicar" i "comprendre" en la seva totalitat no sols el comportament propi (amb l'estabilitzaci emocional que això suposa) sinó també el dels "altres" (no devots), ajuda, en molts casos, I equilibrar o millorar relacions sòcio-familiars abans desnormalitzades ${ }^{17}$.

En aquest context, els devots que ho desitgen poden efectuar visites periodiques als para o familiars, contactar amb persones que no pertanyen al grup per aspectes de tipus jurídic, pe motiu de transaccions econòmiques, de serveis d'infraestructura, o simplement per divulgacio doctrinal. S'interessen pels temes socials que facin referència a l'Associació i procuren estar mínimament informats dels assumptes "materialistes" de caire general. Tot i amb això, s'entén que el distanciament respecte a les "coses mundanes" no només facilita la concentració en el vessant espiritual sinó que és el seu principal requisit.

Les famílies que no viuen als temples tenen precisament més dificultats per mantenis l'atmosfera idònia d'espiritualitat, ja que les condicions socials, familiars i laborals en què estan immerses incrementen la "sociabilitat materialista" i, amb aquesta, les esmentades qüestions pràctiques. En conjunt, les xarxes de relacions dels devots casats que fan "vida social" i dess membres de la congregació, en la mesura que concentren més coactors de paper aliens a l'Associació, adquireixen unes connotacions totalment diferents a les dels devots que fan "vide monàstica", i s'organitzen d'acord amb l'ambivalència material i espiritual de compromisos.

Però en qualsevol cas, a Brihuega, la comunitat espiritual és la metàfora de la casa i th familia, i a nivell de relacions locals, la frontera simbolica "intermons" es manifesta en d manteniment d'un cert estranyament granja Hare Krisna-poble. La possible "contaminacio ideologica-social" recíproca és percebuda com a no gens rendible per cap d'ambdues parts.

${ }^{16}$ En aquest sentit, el Gita preveu: "Uno no debe ser considerado un ser humano perfecto a menos que despierte al posición de examinar su sufrimiento (...) Aquellos que comienzan a inquirir porqué sufren, o de dónde vinieron y adón irán después de la muerte, son los estudiantes idóneos para comprender el Bhagavad-Gita". (Bhagavad-Gita, 1978:10).

17 Un informant explica: "la relación con tus familiares mejora. Ahora están eacantados conmigo. A mí antes m echaban de casa. Tu no robas, no haces daño, eres amistoso con todos, tu carácter mejora....Antes yo era uraño, tn así... ¡sí, ¡no!, ¡me interesa!...Igual de la ira, cuando me interesaba algo era un poquito dulce, cuando me decian 'haz algo' me ponía muy enfadado. Ahora no, saben que pueden contar conmigo para lo que sea que no pasa nada". (G., 14-II-92). 
Des de l'estadi d'investigació on em trobo, interpreto que l'adhesió al Moviment Hare lisna té un caràcter voluntari, si bé en l'adscripció de nous membres funcionen recomanacions ipartit de xarxes d'amistat de conviure amb el grup i experimentar una vida espiritualitzada, en mecial si en l'individu predomina la problemàtica i el desencís social ${ }^{18}$. Aixo remet a les dues ares de la moneda esmentades més amunt (i no exclusives dels col-lectius no legitimats): la muntat de prèdica $i$ ajuda al pròxim d'una banda, i la necessitat d'incorporació de fidels per a la mpoducció i desenvolupament de la institució, d'una altra. De totes maneres, l'opció definitiva és pronal i el tema central està, repetim, en el desig de canvi ontologic latent en l'individu i que husca formes concretes d'expressió.

En aquest procés, sovinteja una experiència mística inicial bastant intensa o si més no monfortant en sentir i cantar el Maha-mantra Hare Krisna, i també una sensació d'aprenentatge mogressiu i continuat en la direcció adequada des del moment en què es decideix la integració. l"entrenament" 19 sincer i decidit en la vida espiritual amb predomini de l'esforç personal i l'ànsia k superació són elements determinants pel que fa a l'adhesió i posterior permanència estable en dMoviment Hare Krisna ${ }^{20}$.

D'altra banda, els factors externs de motivació (ritmes musicals i ornamentació de les matges sagrades fonamentalment), tal com són percebuts pels devots i aquí s'interpreten, tenen una tunció complementària, és a dir, actuen de reforç per als novicis en el "despertar" consciència de lisna o manifestar aquell desig latent de transformacio. Un desig que sembla tenir el seu origen, om assenyala Andrés Tornos, en la recerca interior d'una "autotranscendència" emergida de "la móncia dels individus a buscar significats per si mateixos, a trobar formes de relació i mmunicació humana satisfactòries i a sentir el plaer d'allò nou i misteriós" (Tornos, 1989-90:36); $b$, en un context on les imatges d'identitat desitjades es materialitzarien o explicarien per complet, pasibilitant aixf un reequilibrament global de la persona ${ }^{21}$.

"L L'habituació progressiva a nous ritmes bio-psico-socials en el marc d'un procés global de mocialització/reenculturació, tendirà a atenuar aquests factors i facilitarà la percepció d'objectius concrets, l'adquisició de wi de l'ordre, organització i responsabilitats, i l'afany de superació personal en un àmbit comunitari caracteritzat per la mopleta harmonia relacional. L'assessorament i suport per part dels considerats més avançats espiritualment jugarà un paper walt important en aquest sentit; el nèffit, una vegada iniciat i convertit en devot, tindrà en la figura del mestre espiritual ivu constant guiatge personal.

${ }^{19}$ El terme "entrenament" ha estat una manera de conceptualitzar el procés de formació espiritual per part d'algun dels ilornants, que vindria a coincidir amb la noció d'aprenentatge de rol.

${ }^{x}$ Un informant Hare Krisna, respecte al tema de la pressí6 coercitiva i el "rentat de cervell", argumenta: "N'bi ha m wr un poc innocent per creure's estes coses, penso jo, en ol sentit de què un procés espiritual que exigeix tant de tu mix....jala fora veritat, així la vida espiritual no nos costaria res, seria coser i cantar, i quan te'n mors, pues te'n vas i abon espiritual i ja està, amb el cervell ben rentat. Clar, quan tu ja comences un proces des del primer dia, que $t$ 'has ilukar a les quatre, tens de cantar les rondes, que coste una barbaritat, sobre tot al principi. Al principi jo me'n recordo we m'esforçava una barbaritat $i$ després sempre tens desitjos, desitjos sexuals...tens que luchar contra tot...un poc hasta w watas mb́s o menos situat $i$ veus que claro, ahí no es tracta de rentat de cervell, des del primer moment aix $\delta$ ho veus. Oriment l'esforç l'has de posar tu, si no vols posar-lo pues te'n vas". (T., 31-I-93).

Un altre, després d'opinar que hi ha multiplicitat d'instàncies i processos socials que s'orienten a "rentar el cervell" wh individus, continua: "...o dando otro enfoque al tema: si estamos lavando, ¿qué es lo que lavamos?: lavamos la envidia, heodicia, la lujuria, la ira...del corazón de la gente; eso no es malo para la sociedad". (H., 22-X-92).

${ }^{21}$ Textualment $d$ 'un informant Hare Krisna: "Hi ha una cosa molt forta quan una persona es fa devot $i$ aixd es mrobeix des del primer moment, que és que de repent trobes l'explicacio de tot allb que estaves buscant $i$ que pensaves we no ho trobaries mai. De repent trobes resposta a tot allo que volies saber $\mathrm{i}$ que pensaves que no hi havia resposta. heque arriba un moment que penses que no hi ha resposta (...) Aquesta resposta mental o intelectual et dóna una tranquilitat 
Des de la metàfora i a mode d'hipòtesi, podríem parlar d'identitats diverses però amb components constitutius força afins, que, zelosament desats al primari i inalienable "calaix" de $\mathrm{h}$ pròpia personalitat, simbolitzen, a nivell d'experiència, tant una confusió normativa permanent $(0)$ anomia privada) com una insuficiència essencialista que tendeix a saturar, donat l'esgotament $\alpha$. recursos socials (o d'oferta d'aquests) per satisfer-la. Aquest "calaix", que només espera obrir-ø a qui vulgui mirar al seu interior i atendre el seu contingut, s'obrirà de bat a bat a una instituoid que "escoltarà la seva veu, li dirà allo que vol sentir i li proporcionarà tot el que vol palpar'. L'obtenció d'una resposta teista-existencialista global cobrirà tota una sèrie d'aspectes vitals o hi havia una virtual "deficiència"22, tot garantint una estructura intel-lectual solida a partir de la qual la immediata pràctica individual té una explicació completa i sense fissures ${ }^{23}$. Tuł "deficiències", que quedarien esmenades de forma ajustada gràcies a l'aplicació estricta $i$ sistematitzada de plantejaments filosofico-pràctics adequats o encaixats a cadascuna d'elles, d'um manera molt general, serien: desubicació social (falta de feeling respecte a valors i objectiu dominants i a les pautes conductuals objectivades socialment); inestabilitat emocional (inseguretet generalitzada i dubtes permanents); manca de relacions humanes plaents (incomunicacio, desatencio o incomprensió d'expectatives, falta de suport i absència de models a seguir); indefinició d'objectiu concrets i mancança de directrius orientadores (pors constants respecte al futur personal i a le pèrdues o no llogres i, per tant, por a la infelicitat que d'aixð es deriva); necessitat d'evasió de la realitat (evitació latentment reflexiva i buscadora de "quelcom més"); vida desnormalitzada que provoca el "pensar massa" i la indeterminació permanent, i, en suma, manca de llibertat en el se sentit més general (producte de la desubicació i insatisfacció social generalitzada). Sintetitzant, tres serien els aspectes bàsics que la institució proporcionaria als seus membres: coneixement, seguretat i prestigi (sobretot en el nivell de l'autoestima). Cada un d'aquests es gestaria en d context d'un procés resocialitzador que comporta la interioritẓació generalitzada de nous hảbits, actituds, normes, creences i valors característics d'una cosmovisió essencialment diferent a l'occidental.

En definitiva, el marc institucional Hare Krisna donaria $\cos$ a una dinàmica de canni

molt gran; una tranquilitat molt gran i una realització molt gran". (V., 26-XI-92). O d'un altre: "El Movimiento para h Conciencia de Krisna es como un árbol de los deseos, todo lo que puedas desear lo obtienes". (G., 14-11-93).

22 Evidentment, interpretem "deficiència" en tant que posada en relació a una manca d'afinitat individual respecte al conjunt de valors i objectius dominants en els esquemes de la societat occidental. Així, seguint la hipdtesi del "déficit social" tindriem que: determinats col.lectius sòcio-religiosos no legitimats, organitzats en grup secundari de relacions, compensariet la debilitació de llaços de grup primari (caracteritzats per l'associació ítima "cara a cara" i la cooperacio) restituint-los pet mecanismes institucionalitzats basats en el fort compromís individual i estrets vincles de solidaritat. Com a estructure "intersticials" de resocialitzacio i/o reenculturació, aquests col.lectius, tendirien d'alguna manera a "substituir" les "esquerdes" deixades per algunes institucions hegemðniques, tradicionalment encarregades del procés socialitzador i sistemes de representació darrera dels quals estan tots $\mathrm{i}$ cada un dels codis de valor que la cultura manté. Tal "substituci6" " percebria socialment com un perill especial ja que pot implicar la subversió progressiva de valors culturals fonamentali $i$ posaria en marxa diferents processos de consens i control social per frenar el seu desenvolupament.

23 Un informant ho explica de forma ben precisa: "Con la práctica del proceso de conciencia de Krisna tu vas adquiriendo una percepción de Dios concreta. Sabes, además, que estás situado en un proceso que tiene unos objetivor concretos, no es una cosa que no sabes a donde vas ni nada de eso, si no que sabes que vas a obtener amor puro. No necesitas nada más de satisfacción externa, no necesitas ni drogas, ni tabaco, ni alcohol, ni irte de marcha de vez en cuacto (...) a nivel de realización intelectual tu inteligencia está satisfecha, tienes una filosofía que no te falla. A nivel cultural tienta la cultura prácticamente más amplia del planeta* (G., 14-2-93). 
aistencial individualitzat, però amb variables motivacionals de fons recurrents $\mathrm{s}^{24}$, organitzada al whtant dels forts lligams de fraternitat propis de tota comunitat espiritual, i, en principi, ho faria funa manera força eficaç, ja que la majoria dels seus membres coincideixen a fer una valoració molt positiva de la situació en què es troben i no es plantegen en cap moment un retorn al passat. trob a nivell de percepció social aquesta eficàcia es considera il-legítima, en tant que passa a ser worada en termes de coerció i control "voraç-reclusiu" envers els individus.

Des de la Psicologia Social ens arriba el concepte de persuasió coercitiva (Rodríguez, (52), que funcionaria de basament teòric a aquest tipus d'interpretació. Definida com "el ejercicio weliberado de una persona o grupo de recurrir al uso de la fuerza para influir en las actitudes o moductas de otros, con el objeto de alcanzar algún fin preestablecido" (59), es distingeix d'altres bmes d'influència en l'aplicació de tècniques de pressió psicològica encaminades a transformar t forma forçada les percepcions, creences i actituds dels individus. Aquestes estratègies, que mons l'autor actuarien en dues direccions fonamentals: a/ augmentant de vulnerabilitat del wbjecte, i b/ manipulant-lo a ell i el seu entorn per tal d'implantar-li una nova identitat, es uncteritzarien per l'atemptat que suposen a la llibertat i a la integritat psíquica de la persona.

Rodríguez reconeix que "en buena parte de la persuasión socialmente tolerada, y se mbreentiende que considerada mayoritariamente voluntaria, hay algún grado de coerción" (109) ique molts dels factors a considerar dins les diferents tècniques coactives es poden fer extensibles Iultres àmbits socials i organitzatius exempts de definició "sectària" tals com: les denominades ivtitucions totals ${ }^{25}(112)$, diversos "sistemas de aprendizaje intensivo" (113), "congregaciones ritiosas" (121 i 123), "a quienes ostentan el poder en cualquier organización" (127), "creencias yprácticas de las religiones establecidas" (131), "en el proceso de socialización de un individuo" (M), etc. Per aquest motiu, s'entén que el fonament distintiu entre les anomenades sectes mercitives i altres instàncies socials "es pues más una cuestión de grado de aplicación que de too de técnicas" (80) i, a efectes analítics, s’assenyala la importància operativa d'establir la tontera entre persuasió coercitiva i persuasió voluntària "en el punto que separa las limitaciones W la libertad toleradas de las inaceptables" (109).

Penso que la importància utilitària d'aquests criteris radica en el fet que han de servir-nos te nivell referencial al tractament rigorós dels elements que intervenen en la construcció de

\footnotetext{
${ }^{2}$ Es evident que els trets exposats no es poden aplicar a tots $i$ cadascun dels devots Hare Krisna, es a dir, no mafiguren el "retrat robot" independent de l'individu-membre, sinó que, com a producte de la interacció multifactorial, es woon de forma creuada i matisada on segons quins casos. D'altra banda, poden ser perfectament propis de persones que wi s'ban sentit atretes per un grup religiós de tals característiques o similars, per la qual cosa, han de ser entesos només n wormes relatius.

Però el que sf es vol posar molt en dubte, per aquest cas, són dos factors que apareixen habitualment en el disseny uperfils propiciadors de la dependencia a les anomenades "sectes destructives" (Rodriguez, A./ González, S., 1989: 52): "urtocia d'un sistema de valors o creences arrelades" i "patir algun tipus de psicopatologia". Aquests oon d'entre els weetats pels autors, justament els que poden impulsar de forma ràpida connotacions distintives respecte al comú $i$, en mengìneia, generar processos socials d'estigmatització no sempre justificats.
}

${ }^{25}$ Recordem la classificació de Goffman, E., Op. cit., 18-19: "En primer término hay instituciones erigidas para cuidar 1 las personas que parecen ser a la vez incapaces e inofensivas: son los hogares para ciegos, ancianos, huérfanos e wijentes. En segundo grupo están las erigidas para cuidar de aquellas personas que, incapaces de cuidarse por á mismas, maxínyen además una amenaza involuntaria para la comunidad; son los hospitales de enfermos infecciosos, los hospitales miquiltricos y los leprosarios. Un tercer tipo de institución total, organizado para proteger a la comunidad contra quienes westituyen inintencionadamente un peligro para ella, no se propone como finalidad inmediata el bienestar de los reclusos: menecen a este tipo las cárceles, los presidios, los campos de trabajo y de concentracín. Corresponden a un cuarto grupo intus instituciones deliberadamente destinadas al mejor cumplimiento de una tarea de carácter laboral, y que solo se wifican por estos fundamentos instrumentales: los cuarteles, los barcos, las escuelas de internos, los campos de trabajo, Grenos tipos de colonias, y las mansiones señoriales desde el punto de vista de los que viven en las dependencias de mricio. Finalmente, hay establecimientos concebidos como refugios del mundo, aunque con frecuencia sirven tambien para h formación de religiosos: entre ellos las abadías, monasterios, conventos y otros claustros. 
diferències valoratives respecte a comportaments sòcio-institucionals substancialment molt simila o parells. Es a partir d'aquí que podem arribar a comprendre la naturalesa de tals comportamer i les circumstàncies individuals i socials que desencadenen. Difícilment podrem fer-ho -alment sense perdre certa precisió teòrica- baixant als exemples excessivament estàndards $i$ extrems (e. refereixo, seguint la referència de Rodríguez, a grups d'ideologia política radical i a col-lectin religiosos de fanatisme exacerbat), ni tampoc recolzant el nucli del treball empíric en la reproduca exclusiva de fonts orals també bastant estàndars i extremes (ja sigui en excés crític per procedir d persones que han abandonat els models d'estudi o en excés acrític per venir dels qui estan vinculat aferrissadament). Considerem que el salt qualitatiu és massa important i que recondueix a confusió inicial, ja que la percepció social respecte al fenomen "secta destructiva" no acostuma reduir-se a aquests exemples. A més, tornen a sorgir interrogants tals com: què passa amb $\mathrm{k}$ "sectes" que són anomenades així en to desqualificador però que no són paradigmes de coerció destrucció)?; i amb la resta de col-lectius que no reben aquest nom però utilitzen estratègies coacció?; és que només serien intolerades com a tals aquelles definides així des de l'ordre establer (amb institucions religioses incloses)?; i encara: quines són i com s'expressen les limitacions d llibertat imposades per aquest ordre a nivell d'imatges socials, per tal d'establir la tolerància intolerància dels col-lectius que, al seu torn, limiten llibertats individuals?

Totes aquestes i moltes altres són qüestions importants que cal intentar resoldre, ja que fragmentació explicativa dels fenomens pot alimentar grups d'interès i traduir-se pel que fa l'opinió pública en reduccionismes que associen "tot col-lectiu minoritari no establert" amb "to" persuasió coercitiva o destructiva", i també en incongruències convencionalistes del tipus: "ct persuasió coercitiva n'hi ha arreu i és molt variada, tant que hom pot assumir-la i fins i tot arribe a comprendre-la. Però, això sí, n'hi ha una que és rotundament inacceptable: la que ningú accepta la inacceptada socialment".

Per això, sense pretendre posar en dubte l'existència de tècniques de pressió coercitiva el fet que determinades instàncies socials i confessions religioses les utilitzin de forma deliberad i sistemàtica, des d'aquí es recalca la necessitat de contextualitzar la persuasió coercitiva en marc més ampli, que es correspongui, com hem vist, a la seva amplitud social.

En primer lloc, considerant aquells "absolutos que guardan ínfimo grado de certeza. Psicología Social" (66) de T. Robbins i D. Anthony (1980): a/ que la transformació radical de personalitat o de la identitat pot ser producte d'una autèntica conversió b/ que la submissió a u líder, l'adhesió cega a una doctrina o el sotmetiment de la voluntat intel-lectual poden so simplement accions voluntàries (i fins i tot, en alguns casos, percebudes a consciència com un forma d'alliberament). D'altra banda, per què tot canvi en la personalitat o en les actituds had ser necessàriament induït de forma artificial i coactiva des de l'exterior? Per què es descarta l'opí volitiva? Es descarten així tots els impulsos vocacionals?; c/ que el sotmetiment a tècniques pressió coercitiva no sempre implica que les actituds $\mathrm{i}$ conductes siguin iniciades i mantingude involuntàriament. L'experiència i el compromís poden evolucionar vers una plena voluntarietat; que sovint només una minoria dels sotmesos a persuasions coercitives típicament "dures" "manifestes" tendeix a "suportar-les" de forma constant instal-lant-les a la seva vida. Cal tenir compte la gran quantitat de desercions entre els convertits, així com valorar les seves opinio respecte als processos coactius que han viscut conjuntament amb les dels hipotètics "escla mentals" d'aquests processos; e/ que l'autèntica experiència espiritual i el compromís ideolog poden ser només personals i no estar mediatitzats per reforços socials. Podréem afegir encara qu si existís prèviament o posteriorment tal mediatització, aquesta pot ser assumida i compresa forma voluntària, fins i tot amb l'objecte d'evitar angoixes cognitives personals i/o espirituals. el sentit religiós, per exemple, els vots d'obediència a l'estructura institucional mediatitzari l' "autenticitat primària".

En segon lloc, i com ja hem apuntat abans, cal observar no solament la verificació de l estratègies coercitives en contextos definits com a "sectaris", sinó tenir en compte la multiplici 
d'àmbits i estaments on semblen manifestar-se amb major o menor intensitat i perseverància. Però procedint amb molt rigor empíric sobre la "qüestió de grau" i llur relativisme sòcio-estructural. Nixd és, analitzant quin paper juguen certes instàncies socials i institucionals que poden utilitzar "también en alguna medida tales técnicas" (80) en la projecció d'imatges i estereotips derivats en prejudicis que modifiquen "el grau de la qüestio" i amb aquesta, les interpretacions en general.

En tercer lloc, catalitzant la variació dels processos de legitimació partint de les circumstàncies sòcio-històriques, els mecanismes d'interacció social i institucional, i els sistemes d'interès i de poder. En aquest sentit, caldria veure: a/ com incideix la tradició pel que fa a usceptibilitzar els "fets objectius" d'oposar-se l'individu coactivament mitjançant el procés socialitzador; b/ com, a partir d'aquí, al món institucional se li fan necessàries maneres de ser explicat $\mathrm{i}$ justificat socialment $\mathrm{i}$ també l'elaboració de diferents organismes que executin el control wial per supervisar i corregir les desviacions respecte a les normes establertes (Berger, P./Luckmann, Th., 1988); i encara, de forma més precisa, c/ les diferents significacions que l'activitat humana genera sobre un mateix fenomen o institució.

Englobant aquests temes des d'una perspectiva "històrico-culturista", tenim que: les interaccions comunicatives (simboliques) han de ser analitzades per descobrir les contradiccions scials i les relacions de poder que s'amaguen en els significats de tals interaccions. Cal observar les condicions socials en què té lloc la comunicació, ja que la constitució de símbols i llur conceptualització reflecteix sempre el caràcter de les relacions de poder en una formació social, així com una tradició cultural històricament compartida. Des d'aquest enfocament, els fets i significats d'una acció estan configurats per la tradició cultural i per allo que aquesta considera possible (Ulin, R., 1990). A partir d'aqui, i pel que fa al tema que ens ocupa, poden estudiar-se fenomens tals com l'orientació individual "desviada" cap a un marc de representacions "desviat" (la secta en aquest as) i la resposta de la societat respecte a tal conducta en funció del ventall d'opcions de què disposa.

En quart lloc, en el context interpretatiu que les expectatives i pràctiques que es prenen com a representatives de tota la vida social en realitat són parcials, limitades i disposades amb vista a la legitimació de l'ordre existent, entrariem en el camp analític de la reacció social i, més concretament, en l'examen de com els interessos i l'autoritat apliquen i mantenen un cos normatiu que intervé directament en la formació dels significats socials dels actes i la seva qualitat. Segons Taylor, Walton i Young (1990:186): "Entonces puede verse claramente que el resultado -la concepción cotidiana de lo que está bien, el mundo de sentido común en el que viven los normales y los desviados- ha sido condicionado por las arraigadas posiciones de poder y el interés". Enllaçant amb aixd, convenim amb L. Tylor y H. Graham (1972) que: "sólo determinadas creencias servirán de sostén a determinados sistemas sociales (...) si bien una acción puede describirse de cualquier manera, sólo algunas descripciones o motivos sostendrán permanentemente una acción (...). Si el motivo es una forma de concebir la acción social, de hacerla inteligible, entonces hay ciertas instituciones que favorecen determinadas concepciones que niegan motivos a otras, basándose en que sus acciones no reunen los requisitos de procedimientos que justifican la asignación de un motivo y la aplicación de palabras como "deliberado" para calificar el comportamiento de un individuo" (Cfr. Tylor..., Op. cit., 224).

Una vegada plantejades aquestes consideracions de contingut, per acabar, tornem al cas concret que ens ha ocupat a l'article.

En un règim de vida monàstic, ja sigui legitimat o no (cas Hare Krisna), i definit per L. Coser com un espai on els monjos "s'aparten del món en una recerca contemplativa de la santedat per disciplinar i sotmetre la seva naturalesa rebel i refrenar els seus impulsos egoistes i, en comunió amb virtuosos religiosos ungits pel mateix ideal, s'humilien i se sotmeten a les experiències de la col-lectivitat" (Coser, Op. cit., 115), els principis espirituals impliquen per si mateixos una renúncia explícita a les denominades "formes d'existència mundana". En aquest context, la base del control que la institució projecta i exerceix sobre els seus membres passa per refusar qualsevol 
conducta relativa a l'incompliment deliberat i reiterat de la normativa comunitària que, per la seva naturalesa, posi en perill l'ordre intern establert. Així, la comunitat no faria més que aplicar dins el seu "recinte espiritualista", i a escala "microsocial", mecanismes de control pre-establerts des del sistema religiós institucionalitzat global on s'insereix, el qual, al seu torn, roman impregnat per l'estructura conceptual cultural més general que li dóna significat simbòlic. Altrament, el comportament religiós de tipus congregacional se centraria més al voltant d'una mena d' "autocontrol" o de responsabilitat personal en coherència amb les creences i la institució que les representa.

En aquests nivells d'anàlisi, la renúncia a les directrius socials marcades des dels canals primaris de socialització i, amb aquesta, a la cosmovisió occidental en el seu sentit més general, per accedir a una institució que simbolitza un altre context sòcio-cultural $\mathrm{i}$ una cosmovisió essencialment diferent a la d'orientació, plantejaria una problemàtica especialment greu des del punt de vista religiós i sociològic. L'acció de trasvassament ideologico-valoratiu per conversió espiritual implica en aquest cas una "desviaci6" radical i polar respecte al que ha estat definit com el "cam! recte". I és per això que el sistema religiós establert i l'organització político-civil, executors històrics del control social, estigmatitzaran aquest tipus de conducta tot projectant-la socialment a nivell d'idees i representacions en termes de perill extrem o il-legitimitat de les institucions en què es manifesta. Tals institucions serien reprovades en tant que generadores de processos de reeducaci 6 i reintegracio fora dels esquemes pre-establerts dominants i dins uns esquemes que ofereixen tota la desconfiança d'allò diferent i desconegut.

Sintetitzant: el sistema de poders perd el control dels individus i, amb aquest, progressivament el control social en general. La transgressió de la normativa social activa els mecanismes de control i de consens de la societat, els quals justifiquen la seva intervenció ja no com a expressions institucionalitzades del control social, sinó en qualitat de dispositius de supervisió i defensa dels valors culturals que pretenen representar.

\section{BIBLIOGRAFIA}

A.C. BHAKTIVEDANTA SWAMI PRABHUPADA.

1978 Bhagavad-Gita. Itàlia, Bhaktivedanta Book Trust.

1983 Srimad Bhagavatam. Los Grandes Clásicos de la India. Primer canto: la creación, Fondo Editorial Bhaktivedanta, Los Angeles.

BERGALLI, R.

1980 "El origen de las teorías de la reacción social", a Papers, 13. Revista de Sociologia. Barcelona, Península.

BLOFELD, J.

1989

Mantras. Sagradas palabras de poder. Madrid, Edaf.

COSER, L.A.

1978 Las instituciones voraces. México, F.C.E.

ELIADE, $\mathbf{M}$.

1979

El mito del eterno retorno. Madrid, Alianza. 
ELADE, M. / COULIANO, I.

1992 Diccionario de las religiones. Barcelona, Paidós.

GOFFMAN, E.

1988 Internados. Buenos Aires, Amorrortu.

GONZALEZ, $M$.

1983 "Asociación para la Conciencia de Krisna", a GARCIA HERNANDO, J. (Dir.), Pluralismo religioso en Espafia II: Sectas y religiones no cristianas. Salamanca, Sociedad de Educación Atenas.

MAHADEVAN, T.M.P.

$1991 \quad$ Invitación a la filosofía de la India. México, F.C.E.

RENOU, $\mathbf{L}$.

1991 El hinduismo. Barcelona, Paidós.

RODRIGUEZ, A. / GONZALEZ, S.

1989 "De las drogas y de las sectas", a Comunidad y drogas. Cuadernos Técnicos de Estudios y Documentación. Madrid, Ministerio de Sanidad y Consumo.

RODRIGUEZ, A.

1992 El lavado de cerebro. Psicología de la Persuasión coercitiva. Barcelona, Boixareu Universitaria.

RODRIGUEZ, $P$.

1985 Las sectas hoy y aqui. Barcelona, Tibidabo.

SALARRULLANA, $\mathrm{P}$.

1990 Las sectas. Un testimonio vivo sobre los mesias del terror en Espafia. Madrid, Temas de hoy.

SEN, K.M.

1976 Hinduismo. Madrid, Guadarrama.

TAYLOR, I./WALTON, P./YOUNG, J.

1990 La nueva criminología. Contribución a una teoría social de la conducta desviada. Buenos Aires, Amorrortu.

TORNOS, A.

1989/90 "Psicopatología de las sectas religiosas", a Memoria académica. Madrid, Instituto de Fe y Secularidad.

ULIN, R.

$1990 \quad$ Antropología y teoría social. México, S. XXI.

VASANT LAD.

1991 Ayurveda. La ciencia de curarse uno mismo. Buenos Aires, Continente-Pax. 
VEDAVYASA.

1983 Cómo llegar a ser vaisnava. Brihuega/Guadalajara, Ed. Bhaktivedanta (A.C.K).

VEDAVYASA.

1992 "Las glorias del Santo Nombre", a El espiritual, 1. Madrid, A.C.K.

VIVEKANANDA.

1976 Filosofia vedanta. México D.F., Roca. 